\title{
Cardioprotective effects and antioxidant status of Andrographis paniculata in isoproterenol-induced myocardial infarction in rats
}

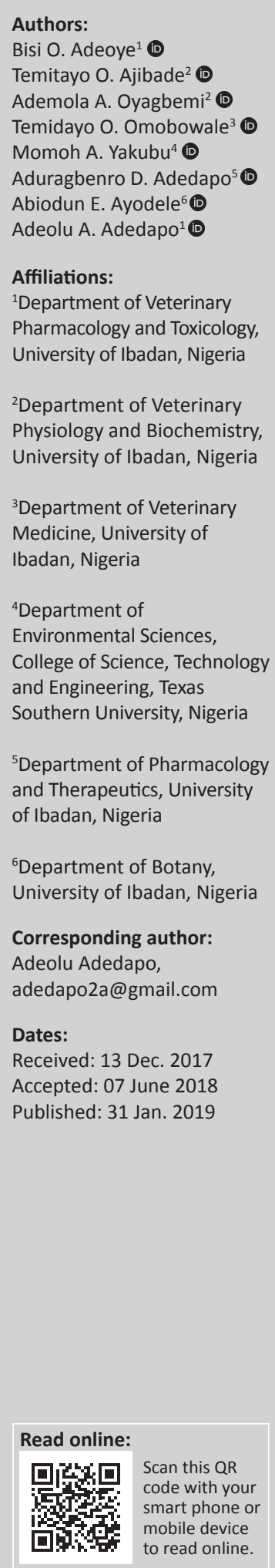

Background: Myocardial infarction has been regarded as one of the fastest killer diseases of modern-day man.

Aim: The protective effect of Andrographis paniculata on isoproterenol (ISO)-induced myocardial infarction in rats was investigated.

Setting: The study was carried out in a laboratory setting.

Methods: Animals were randomly divided into six groups of seven animals per group, and the treatment was as follows: normal control received normal saline for 9 days, isoproterenol group; three extract-treated groups in pre-treatment phase and an extract-treated group in posttreatment phase. The doses were given at 100,200 and $400 \mathrm{mg} / \mathrm{kg}$ body weight for pre-treatment phase respectively while $200 \mathrm{mg} / \mathrm{kg}$ dose was given to the post-treatment phase group. Blood and heart tissues were collected for biochemical assays, haematological and histological analyses.

Results: Myocardial infarction was recorded in ISO group but was corrected by the extracts in both pre-treatment and post-treatment phases. The ISO group experienced a significant decrease in antioxidant parameters, whereas the extract at all doses caused a significant increase in the activities of in these parameters. The extract caused a significant decrease in malondialdehyde content and hydrogen peroxide generation, whereas reverse was the case for the ISO group. Although no significant histopathological changes were recorded for the extract, the ISO group showed marked histopathological changes. ISO caused higher expressions of cardiac C-reactive protein (CRP) and CTnI and decreased the expressions of IL$10 \beta$; but this was the opposite for the extract.

Conclusion: The ethanol leaf extract of $A$. paniculata significantly exhibits cardioprotective effects.

\section{Introduction}

Catecholamines are released under the conditions of stress; hence, they are also administered in circumstances of cardiac stress to sustain blood pressure and cardiac function in patients. These agents are important regulators of myocardial contractility and metabolism, but excess amounts of catecholamines are responsible for damage at cellular level as observed in clinical conditions such as acute coronary insufficiency, transient myocardial hypoxia, angina and subendocardial infarct. Because catecholamines generate reactive oxygen species (ROS), they thus contribute to oxidative stress (Yogeeta et al. 2006; Hussein 2015). ROS can initiate lipid peroxidation reactions and propagate cell membrane damage (Chen et al. 2000). Isoproterenol [1-(30, 40-dihydroxy phenyl)-2-isopropyl amino ethanol hydrochloride] (ISO) is a synthetic catecholamine, which acts as a $\beta$-adrenergic agonist. It has been found to produce stress in the myocardium leading to severe toxicity in the myocardium, thus, resulting in depletion of energy reserve of cardiac muscle cells. It is also known to cause complex biochemical and structural changes leading to cell damage and necrosis (Yogeeta et al. 2006). Some of the mechanisms proposed to explain ISO-induced damage to cardiac myocytes include coronary hypotension, energy depletion, hypoxia, calcium overload and excessive production of free radicals as a result of catecholamine autoxidation (Adameova, Abdellatif \& Dhalla 2009; Rona et al. 1959). To study the beneficial effects of many drugs on cardiac function, ISO-induced myocardial damage was considered as one of the most widely used experimental models (Rona 1985). Several natural products are reported to prevent ISO-induced myocardial infarction (MI) because of their antioxidant activity (Chen et al. 2000; Murugesan et al. 2012; Upaganlawar \& Balaraman 2011; Upaganlawar, Gandhi \& Balaraman 2011). The antioxidant

How to cite this article: Adeoye, B.O., Ajibade, T.O., Oyagbemi, A.A., Omobowale, T.O., Yakubu, M.A., Adedapo, A.D., Ayodele, A.E. \& Adedapo, A.A., 2019, Cardioprotective effects and antioxidant status of Andrographis paniculata in isoproterenol-induced myocardial infarction in rats', Journal of Medicinal Plants for Economic Development 3(1), a49. https://doi.org/10.4102/jomped.v3i1.49

Copyright: @ 2019. The Authors. Licensee: AOSIS. This work is licensed under the Creative Commons Attribution License. 
activities of A. paniculata and its constituents have been reported (Zhang \& Tan 2000; Verma \& Vinayak 2008).

Andrographis paniculata (Burm) Wall ex Nees (Acanthaceae) is an important medicinal plant that is widely used globally (Hossain et al. 2014). The pharmacological potentials of $A$. paniculata such as anti-inflammatory (Sheeja \& Kuttan 2012), immunostimulatory (Sheeja \& Kuttan 2012), hepatoprotective (Trivedi \& Rawal2001), antihyperglycemic (Reyes et al. 2006), antioxidant (Akowuah, Zhari \& Mariam 2008; Kamdem, Sang \& Ho 2002; Singh, Banerjee \& Rao 2001) and cardiovascular activities (Zhang \& Tan 1997) have been demonstrated. The major phytoconstituent of this plant is andrographolide, a labdane diterpenoid. Other bioactive secondary metabolites of the plant such as diterpenoids, diterpene glycosides, lactones, flavonoids and flavonoid glycosides are also present and are involved in antidiabetic, hepatoprotective, antioxidant, antiinflammatory and diverse other therapeutically interesting bioactivities (Akbar 2011; Jayakumar et al. 2013; Parixit et al. 2012).

In this study, the ethanol leaf extract of A. paniculata was used to evaluate the cardioprotective effect of this plant using its antioxidant properties as well as haemodynamics, histopathologic and immunohistochemical changes.

\section{Materials and methods Plant collection and extract preparation}

The leaves of the plant $A$. paniculata were collected from the University of Ibadan Botanical Garden. The plants were identified and authenticated with voucher numbers: UIUIH 2846 by herbarium curator, Department of Botany, Faculty of Science, University of Ibadan. The leaves were cleaned with distilled water and air dried in a wellventilated shady room. The dried leaves were grinded to powder using a blender. The grinded powder was extracted in cold ethanol in a screw-capped flask for $72 \mathrm{~h}$ and shaken at room temperature. The solvent was filtered, squeezed off and evaporated off under reduced pressure in a rotatory evaporator at $40^{\circ} \mathrm{C}$ to obtain semi-solid crude extract which was stored at $4{ }^{\circ} \mathrm{C}$. The stored ethanol extract of $A$. paniculata (EEAP) was then used for the study.

\section{Chemicals and reagents}

Isoproterenol, Biuret reagent, hydrogen peroxide, hydrochloric acid, sulphuric acid, xylenol orange, potassium dichromate, O-diasinidine, sodium potassium tartrate, copper sulphate, ethanol, sodium azide, 2-dichloro-4-nitrobenzene (CDNB), Griess reagent, phosphoric acid, sodium hydroxide, N-(1naphthyl)ethylenediamine, sulphanilamide, distilled water, phosphate buffer saline, creatinine reagent, copper sulphate, trichloroacetate, reduced glutathione $(\mathrm{GSH})$, thiobarbituric acid (TBA), trichloroacetic acid (TCA), ammonium ferrous sulphate, glacial acetic acid, potassium iodide, sorbitol, Ellman's reagent (DTNB), ethanol and urea reagent. All chemicals and drugs used were of analytical grade and obtained from British Drug Houses (Poole, Dorset, UK).

\section{Experimental animals}

All experiments and protocols described in this study were approved by the University of Ibadan Animal Care and Use Research Ethics Committee (UI-ACUREC). Forty-two male Wistar rats weighing $120 \mathrm{~g}-150 \mathrm{~g}$ were obtained from the Experimental Animal Unit of the Faculty of Veterinary Medicine for the study. These animals were allowed free access to standard rat pellets and fresh water ad libitum in the Animal House Unit of the Department of Veterinary Physiology, Biochemistry and Pharmacology, where they were housed with a 12-h light duration. Preconditioning of the rats was performed for 2 weeks before the commencement of the experiment.

\section{Cardioprotective study}

The animals were randomly divided into six groups of seven animals each, and the treatment was as follows: the control (group A) received normal saline for 9 days, group B animals received normal saline for 7 days and thereafter isoproterenol (ISO) at $85 \mathrm{mg} / \mathrm{kg}$ on days 8 and 9. Groups C, D and E animals, on the other hand, were pre-treated with the ethanol leaf extract of A. paniculata at $100 \mathrm{mg} / \mathrm{kg}, 200 \mathrm{mg} / \mathrm{kg}$ and 400 $\mathrm{mg} / \mathrm{kg}$, respectively, for 7 days and thereafter received ISO on days 8 and 9. Group F animals were treated with ISO on days 1 and 2 and thereafter received $200 \mathrm{mg} / \mathrm{kg}$ of the extract for the remaining 7 days.

\section{Blood pressure measurement}

Blood pressure measurement of all the animals was carried out on day 10. Baseline cardiovascular parameters were collected prior to the commencement of the experiment. The equipment used was a non-invasive tail cuff BP monitor, the 6-channel CODA blood pressure monitor for rats and mice. Blood pressure parameters including the systolic, diastolic and mean arterial blood pressure parameters were determined indirectly in non-anaesthetised rats by tail plethysmography with the use of an electrosphygomanometer (CODA, Kent Scientific, USA). The average of at least nine most consistent readings, taken in the quiescent state, following acclimatisation, was recorded per animal.

\section{Blood sample collection}

At the end of the experimental period, blood samples were collected for serum chemistry before the rats were sacrificed by cervical dislocation. The serum in plain bottles was rapidly centrifuged at 4000 revolutions per minute (rpm) for $15 \mathrm{~min}$ and processed for determination of serum myeloperoxidase, total protein, aspartate transaminase (AST), alanine aminotransferase (ALT), and nitric oxide (NO). The heart of each rat was carefully removed and homogenised on ice and then used to assay for some oxidative stress markers and antioxidant parameters. 


\section{Preparation of tissue homogenate}

The heart tissues of the rats were harvested on ice, rinsed with normal saline and homogenised in aqueous potassium buffer (0.1 M, pH 7.4), and the homogenate was centrifuged at $12000 \mathrm{rpm}\left(4^{\circ} \mathrm{C}\right)$ for $15 \mathrm{~min}$ to obtain the supernatant fraction.

\section{Biochemical assays}

Determination of the protein concentrations of the various samples was by Biuret method as described by Gornal, Bardawill and David (1949). To prevent precipitation of $\mathrm{Cu}^{2+}$ ions, cuprous oxide potassium iodide was added to the reagent. The method of Beutler and Kelly (1963) was used to determine the concentration of reduced GSH, whereas glutathione peroxidase (GPx) activity was measured by the method of Rotruck et al. (1973). In this case, hydrogen peroxide was used as substrate to oxidise reduced GSH to oxidised glutathione (GSSG). The estimation of glutathioneS-transferase (GST) was done by the method of Habig, Pabst and Jacoby (1974) using 1-chloro-2, 4-dinitrobenzene as substrate. Superoxide dismutase (SOD) assay, on the other hand, was carried out by the method of Misra and Fridovich (1972) with slight modification. The MDA content was measured in the heart as an index of lipid peroxidation as described by Varshney and Kale (1990). The method of Wolff (1994) was used to measure hydrogen peroxide generation, whereas sulfhydryl (Thiol) content determination was performed by the method of Ellman (1959). The quantification of NO was carried out as previously described by Olaleye, Adaramoye and Erigbali (2007).

\section{Histopathology}

Small slices of the heart were collected in $10 \%$ buffered formalin for proper fixation, and after the tissues have been processed and embedded in paraffin wax, sections of about $5 \mu \mathrm{m}-6 \mu \mathrm{m}$ thick were made and stained with haematoxylin and eosin for histopathological examination (Drury, Wallington \& Cancerson 1976).

\section{Immunohistochemistry of cardiac troponin-1, cardiac C-reactive protein and Interleukin-10 (IL-10)}

The heart tissues obtained from buffered formalin perfused rats were paraffin embedded and then used for immunohistochemistry. Paraffin sections were melted at $60{ }^{\circ} \mathrm{C}$ in the oven, but the dewaxing of the samples in xylene was followed by passage through decreasing concentrations of ethanol (100\%-80\%). Peroxidase quenching in $3 \% \mathrm{H}_{2} \mathrm{O}_{2} /$ methanol was carried out with subsequent antigen retrieval performed by microwave heating in $0.01 \mathrm{M}$ citrate buffer ( $\mathrm{pH}$ 6.0) to boil. All the sections were blocked in normal goat serum (10\%, HistoMark ${ }^{\circledR}$, KPL, Gaithersburg, MD, USA) and probed with cardiac troponin-1 (CTnI), cardiac C-reactive protein (CRP) antibody and IL-10 (Abclonal $\left.{ }^{\circledR}\right)$, 1:375 for $16 \mathrm{~h}$ in a refrigerator. Detection of bound antibody was carried out using biotinylated (goat anti-rabbit, $2.0 \mu \mathrm{g} /$ $\mathrm{mL}$ ) secondary antibody and, subsequently, streptavidin peroxidase (Horse Radish Peroxidase-streptavidin) according to the manufacturer's protocol (HistoMark ${ }^{\circledR}$, KPL, Gaithersburg, MD, USA).

Diaminobenzidine (DAB, Amresco $\left.{ }^{\circledR}, \mathrm{USA}\right)$ was used to enhance the reaction product for 6-10 $\mathrm{min}$ and counterstained with high-definition haematoxylin $\left(\right.$ Enzo $^{\circledR}$, NY, USA), and was thereafter dehydrated in ethanol. Once the slides were covered with cover slips, they were sealed with resinous solution. The immunoreactive positive expression of CTnI, CRP and IL-10 intensive regions was viewed starting from low magnification on each slice and then with $400 \times$ magnifications using a photo microscope (Olympus) and a digital camera $\left(\right.$ Toupcam $^{\circledR}$, Touptek Photonics, Zhejiang, China).

\section{Statistical analysis}

All values were expressed as mean \pm standard deviation (SD). One-way analysis of variance (ANOVA) with Tukey's post hoc test using Graph pad prism 5.0 was also performed, with $p<0.05$ considered statistically significant.

\section{Results}

In this study, MI as seen by significant decrease in systolic, diastolic and mean arterial pressure was recorded in the ISO group but was corrected by the extracts in both pre-treatment and post-treatment phases (Figures 1-3). There was a significant increase in white blood cells (WBC) in the ISO group (Table 1). The ISO group showed a significant decrease in antioxidant parameters, whereas pre-treatment $(100 \mathrm{mg} /$ $\mathrm{kg}$ ) and post-treatment with the extract caused a significant increase in the levels of SOD, GPx, GST and GSH (Figures $4-7)$. The extract caused a significant decrease in MDA content, $\mathrm{MPO}$ and $\mathrm{H}_{2} \mathrm{O}_{2}$ generation, whereas reverse was the case for group $\mathrm{B}$ animals (Figures 8 and 9). The extract at all doses caused a significant increase in the levels of protein

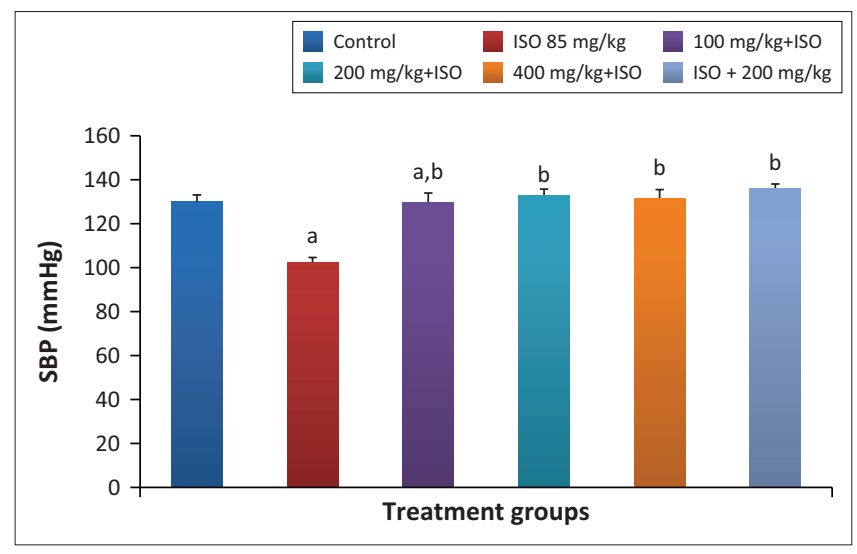

The results showed the effect of ethanol extract of Andrographis paniculata (EEAP) on SBP where values are presented as mean \pm standard deviation.

$a$, indicates significant reduction $(\alpha<0.05)$ when compared with control $(G r p A) ; b$, indicates significant increase $(\alpha<0.05)$ when compared with ISO treated only (Grp B). Grp A (control), Grp B (ISO treated only), Grp C (100 mg/kg AP + ISO), Grp D (200 mg/kg AP + ISO), Grp E (400 $\mathrm{mg} / \mathrm{kg} \mathrm{AP}+\mathrm{ISO}$ ) and Grp F (ISO $+200 \mathrm{mg} / \mathrm{kg}$ AP post-treated). AP, Andrographis paniculata.

FIGURE 1: Effect of the ethanolic leaf extract of Andrographis paniculata on systolic blood pressure (SBP) in isoproterenol-induced myocardial infarction in rats. 


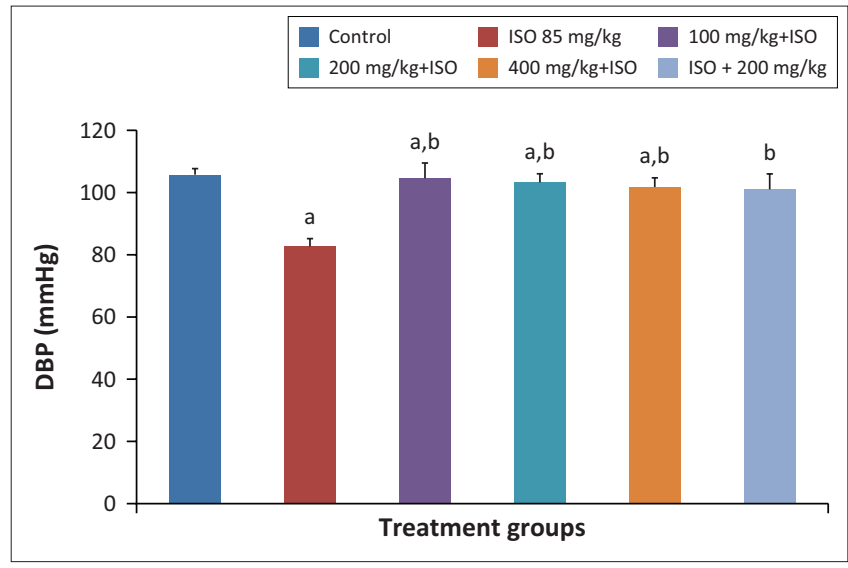

The results showed the effect of ethanol extract of Andrographis paniculata (EEAP) on DBP where values are presented as mean \pm standard deviation.

a, indicates significant reduction $(\alpha<0.05)$ when compared with control $(\operatorname{Grp} A) ; b$ indicates significant increase $(\alpha<0.05)$ when compared with ISO treated only (Grp B). Grp A (control), Grp B (ISO treated only), Grp C (100 mg/kg AP + ISO), Grp D (200 mg/kg AP + ISO), Grp E (400 mg/kg AP + ISO) and Grp F (ISO $+200 \mathrm{mg} / \mathrm{kg}$ AP post-treated). AP Andrographis paniculata.

FIGURE 2: Effect of the ethanolic leaf extract of Andrographis paniculata on diastolic blood pressure (DBP) in isoproterenol-induced myocardial infarction using rats as a model.

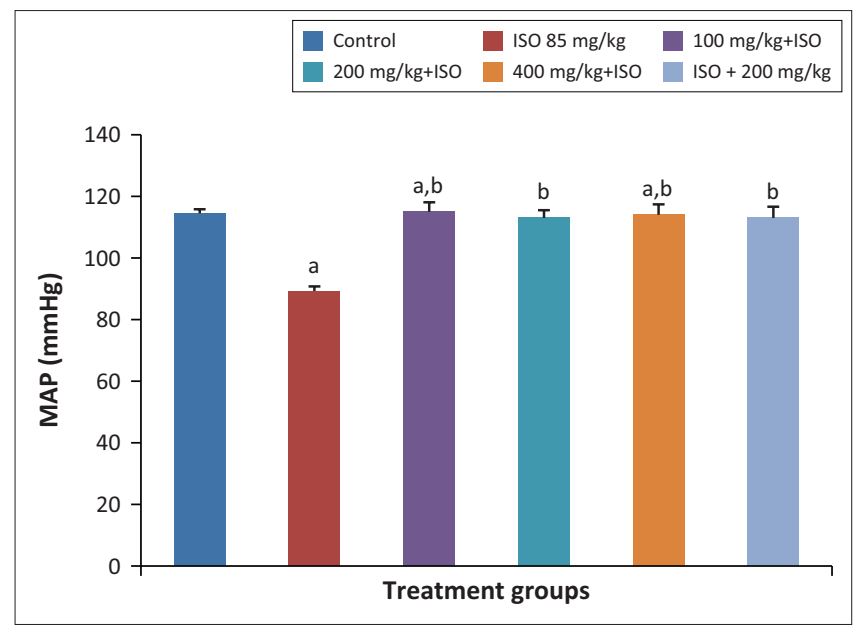

The results showed the effect of ethanol extract of Andrographis paniculata (EEAP) on MAP where values are presented as mean \pm standard deviation.

a, indicates significant reduction $(\alpha<0.05)$ when compared with control $(G \operatorname{rp~A})$; b, indicates significant increase $(\alpha<0.05)$ when compared with ISO treated only (Grp B). Grp A (control), Grp B (ISO treated only), Grp C (100 mg/kg AP + ISO), Grp D (200 mg/kg AP + ISO), Grp E (400 mg/kg AP + ISO) and Grp F ( ISO $+200 \mathrm{mg} / \mathrm{kg}$ AP post-treated). AP, Andrographis paniculata.

FIGURE 3: Effect of the ethanolic leaf extract of Andrographis paniculata on mean arterial pressure (MAP) in isoproterenol-induced myocardial infarction using rats as a model.

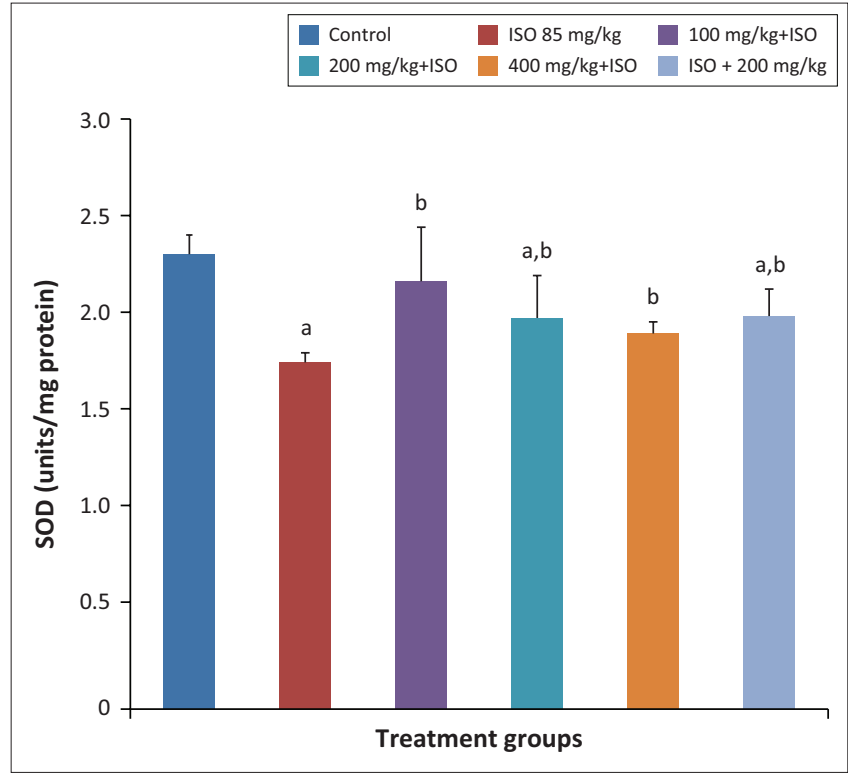

Values are presented as mean \pm standard deviation.

a, indicates significant difference $(p<0.05)$ when compared with control $(\operatorname{Grp} \mathrm{A})$; $\mathrm{b}$, indicates significant difference $(p<0.05)$ when compared with ISO treated only (Grp B).

FIGURE 4: Effect of the ethanolic extract of Andrographis paniculata on superoxide dismutase enzyme in isoproterenol-induced myocardial infarction using rats as a model $(n=5)$.

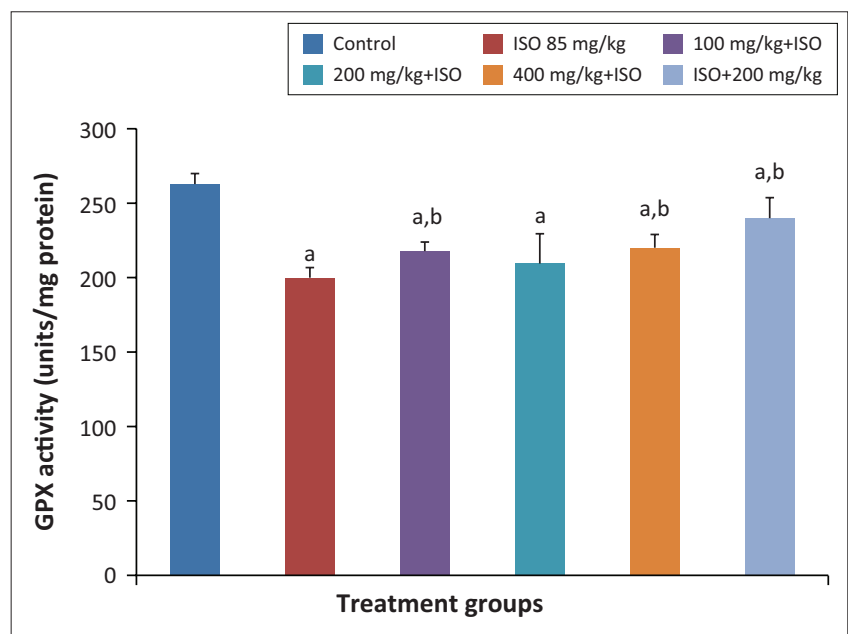

Values are presented as mean \pm standard deviation

a, indicates significant difference $(p<0.05)$ when compared with control $(\mathrm{Grp} \mathrm{A}) ; \mathrm{b}$, indicates significant difference $(p<0.05)$ when compared with ISO treated only (Grp B).

FIGURE 5: Effect of the ethanolic extract of Andrographis paniculata on glutathione peroxidase enzyme in isoproterenol-induced myocardial infarction using rats as a model $(n=5)$.

TABLE 1: Effects of the ethanolic leaf extract of Andrographis paniculata on haemogram in isoproterenol-induced myocardial infarction using rats as a model.

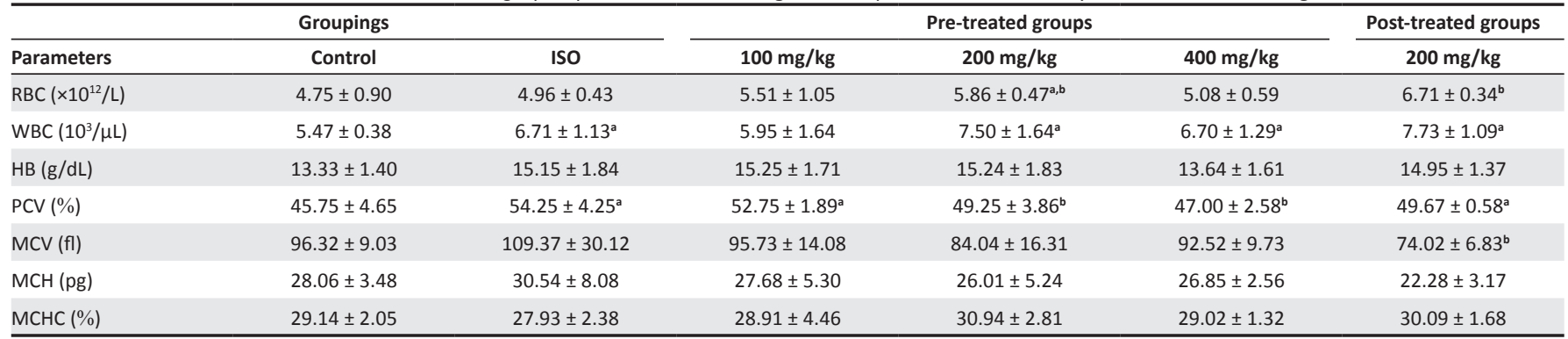

Note: The results showed the effect of ethanol extract of Andrographis paniculata (EEAP) on haemogram where values are presented as mean \pm standard deviation.

RBC, Red blood cells; WBC, white blood cells; ISO, isoproterenol; HB, Haemoglobin; PCV, Packed Cell Volume; MCV, Mean Corpuscular Volume; MCH, Mean Corpuscular Haemoglobin; MCHC, Mean Corpuscular Haemoglobin Concentration.

a, indicates significant different $(\alpha<0.05)$ when compared with control (Grp A); b, indicates significant different $(\alpha<0.05)$ when compared with ISO treated only (Grp B). Grp A (control), Grp B (ISO treated only), Grp C (100 mg/kg AP + ISO), Grp D (200 mg/kg AP + ISO), Grp E (400 mg/kg AP + ISO) and Grp F ( ISO +200 mg/kg AP post-treated). AP, Andrographis paniculata. 


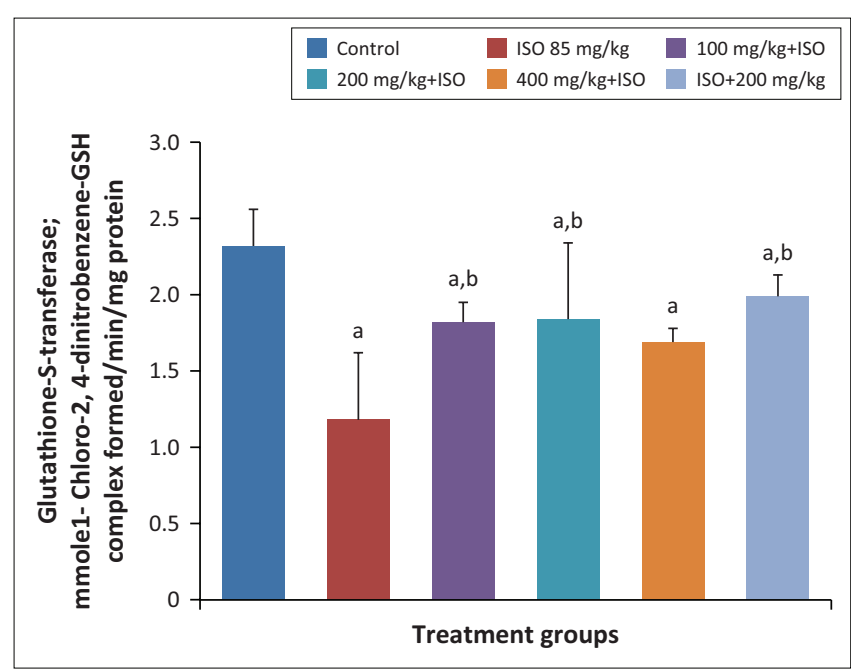

Values are presented as mean \pm standard deviation

$\mathrm{a}$, indicates significant difference $(p<0.05)$ when compared with control $(\mathrm{Grp} A)$; b, indicates significant difference $(p<0.05)$ when compared with ISO treated only (Grp B).

FIGURE 6: Effect of the ethanolic extract of Andrographis paniculata on glutathione-S-transferase enzyme in isoproterenol-induced myocardial infarction using rats as a model $(n=5)$.

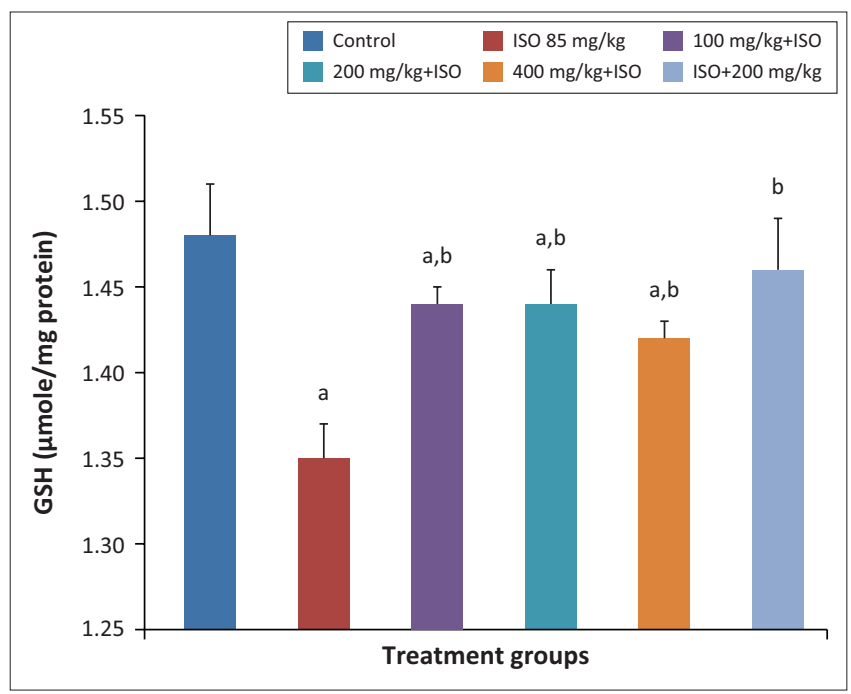

Values are presented as mean \pm standard deviation.

a, indicates significant difference $(p<0.05)$ when compared with control $(G r p A)$; $\mathrm{b}$, indicates significant difference $(p<0.05)$ when compared with ISO treated only (Grp B).

FIGURE 7: Effect of the ethanolic extract of Andrographis paniculata on reduced glutathione in isoproterenol-induced myocardial infarction using rats as a mode $(n=5)$. The effect of $A$. paniculata on reduced glutathione (GSH).

thiols and non protein thiol but a significant decrease in the level of myeloperoxidase in all extract-treated groups except that of post-treatment phase (Figures 10-12). Although no significant histopathological changes were recorded for the extract, the ISO group had marked histopathological changes (Figure 13). Immunohistochemistry showed that ISO caused higher expressions of cardiac CRP and cTn1 and decrease in IL-10 $\beta$ but vice versa for the extract (Figures 14-16).

\section{Discussion}

Andrographis paniculata has long been used as in traditional medicine for the treatment and prevention of various ailments. The active constituent of $A$. paniculata is andrographolide; its medicinal properties have been reported (Tan et al. 2016).

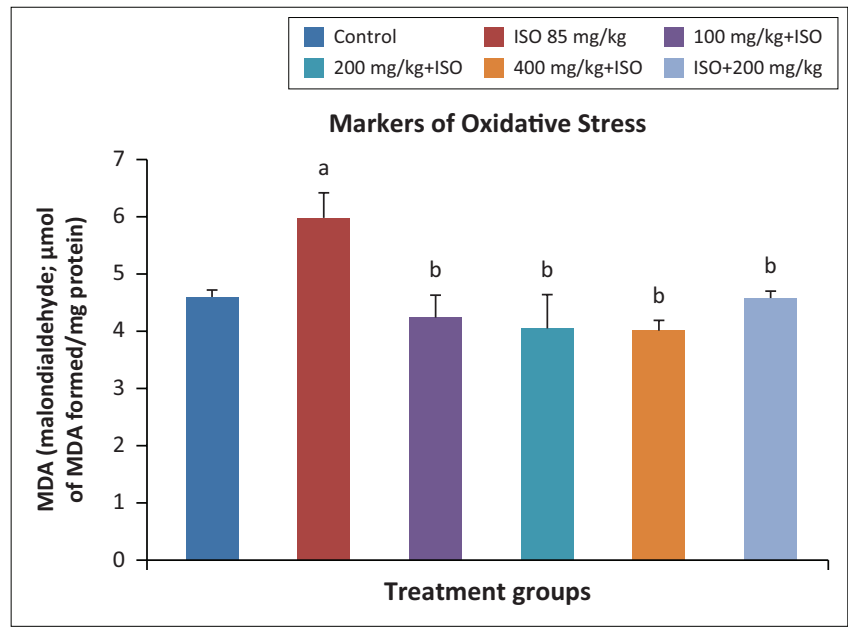

Values are presented as mean \pm standard deviation.

$a$, indicates significant difference $(p<0.05)$ when compared with control $(G r p A) ; b$, indicates significant difference $(p<0.05)$ when compared with ISO treated only (Grp B).

FIGURE 8: Effect of the ethanolic extract of Andrographis paniculata on lipid peroxidation in isoproterenol-induced myocardial infarction using rats as a model $(n=5)$.

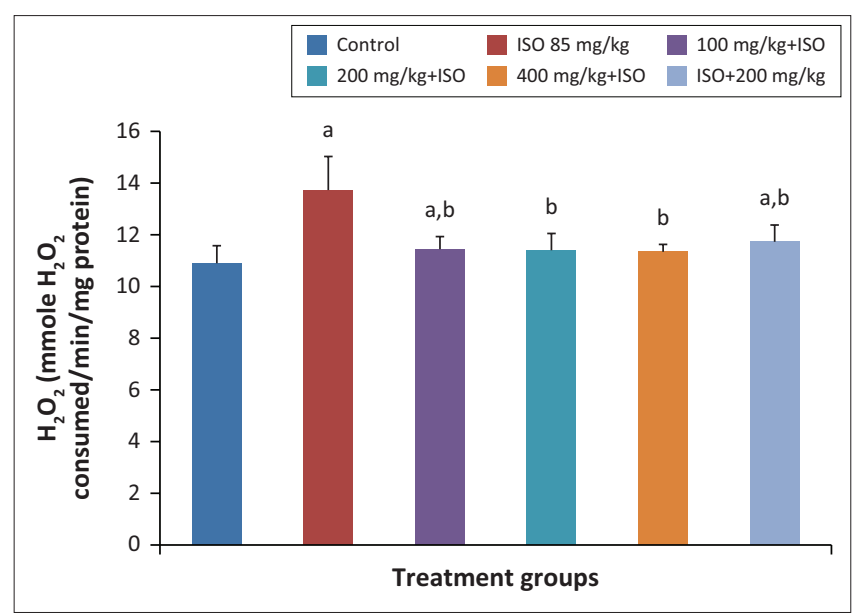

Values are presented as mean \pm standard deviation.

$\mathrm{a}$, indicates significant difference $(p<0.05)$ when compared with control (Grp A); b, indicates significant difference $(p<0.05)$ when compared with ISO treated only (Grp B).

FIGURE 9: Effect of the ethanolic extract of Andrographis paniculata on hydrogen peroxide in isoproterenol-induced myocardial infarction using rats as a model $(n=5)$.

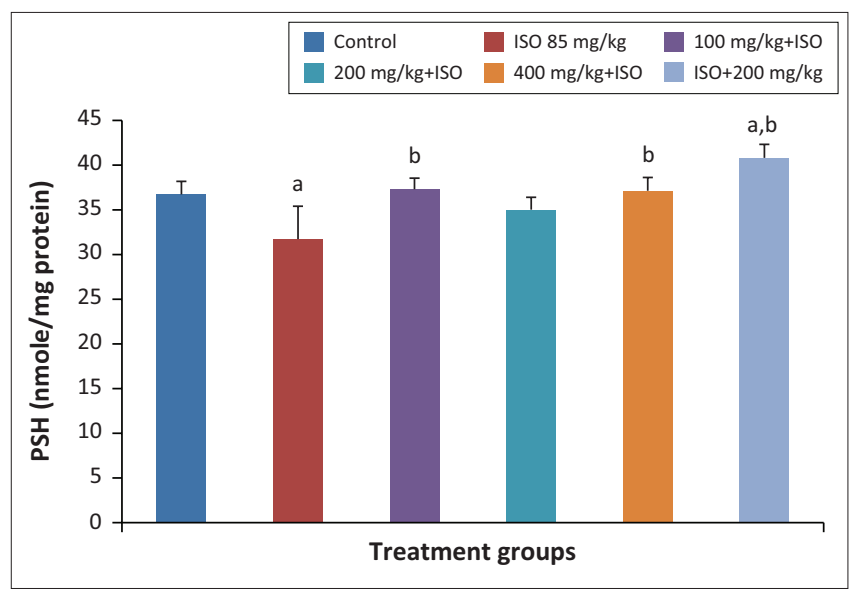

The results showed the effect of ethanol extract of Andrographis paniculata (EEAP) on protein thiol (PT) generation where values are presented as mean \pm standard deviation.

a, indicates significant difference $(p<0.05)$ when compared with control $(\operatorname{Grp} A)$; b, indicates significant difference $(p<0.05)$ when compared with ISO treated only (Grp B).

FIGURE 10: Effect of the ethanolic extract of Andrographis paniculata on protein thiol in isoproterenol-induced myocardial infarction using rats as a model $(n=5)$. 


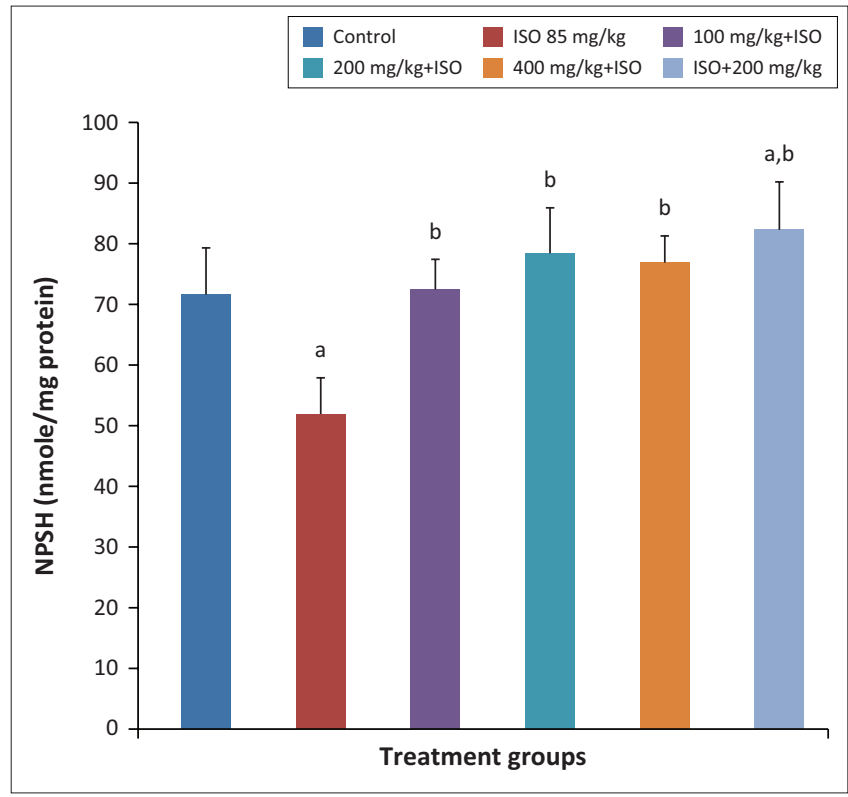

Values are presented as mean \pm standard deviation

a, indicates significant difference $(p<0.05)$ when compared with control (Grp A); b, indicates significant difference $(p<0.05)$ when compared with ISO treated only (Grp B).

FIGURE 11: Effect of the ethanolic extract of Andrographis paniculata on lipid peroxidation in isoproterenol-induced myocardial infarction using rats as a model $(n=5)$.

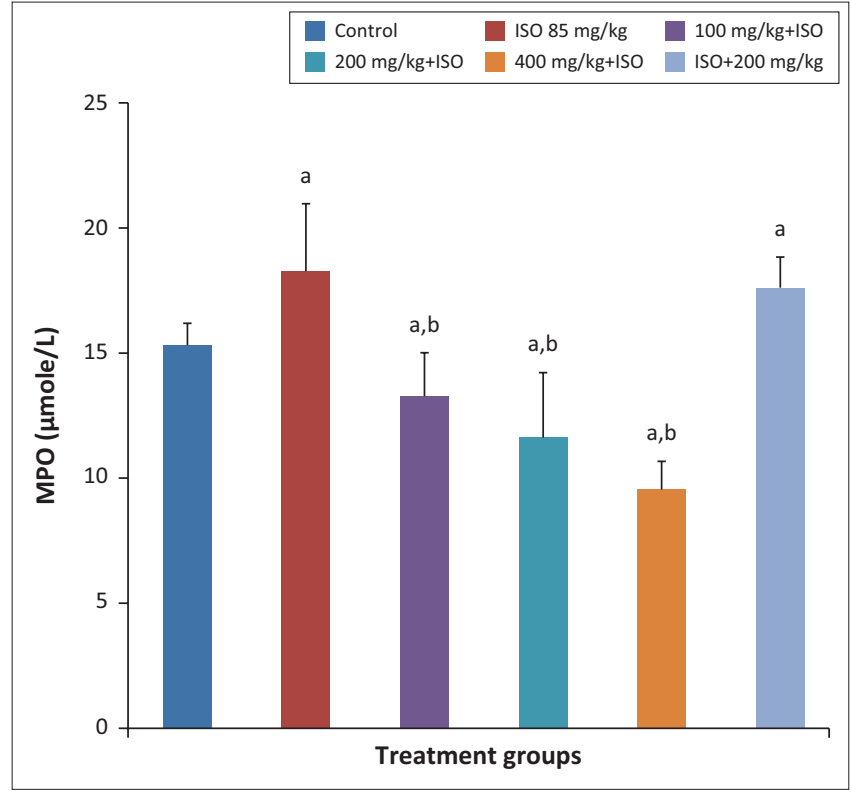

Values are pre

a, indicates significant difference $(p<0.05)$ when compared with control (Grp A); $\mathrm{b}$, indicates significant difference $(p<0.05)$ when compared with ISO treated only (Grp B).

FIGURE 12: Effect of the ethanolic extract of Andrographis paniculata on myeloperoxidase in isoproterenol-induced myocardial infarction using rats as a model $(n=5)$.
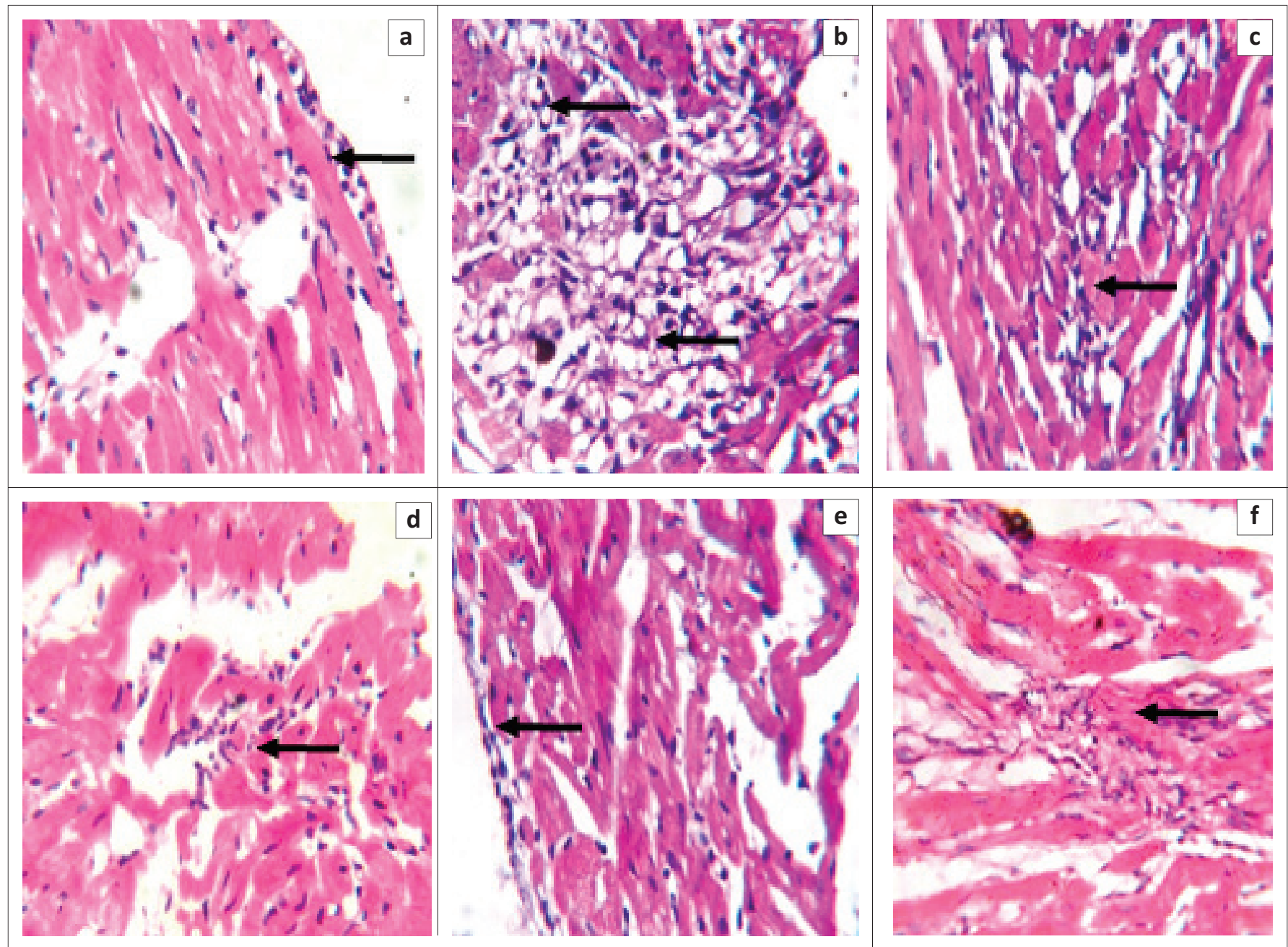

(a) Control - shows no visible lesion. (b) ISO - shows severe infiltration of inflammatory cells. (c) $100 \mathrm{mg} / \mathrm{kg}+\mathrm{ISO}$ and (d) $200 \mathrm{mg} / \mathrm{kg}+\mathrm{ISO}-$ show mild infiltration of inflammatory cells. (e) $400 \mathrm{mg} /$ $\mathrm{kg}+\mathrm{ISO}$ - shows no visible lesion. (f) ISO $+200 \mathrm{mg} / \mathrm{kg}$ - shows mild infiltration of inflammatory cells. Mag. $\times 400$

FIGURE 13: The histopathology of heart from isoproterenol-induced myocardial infarction using rats as a model. 

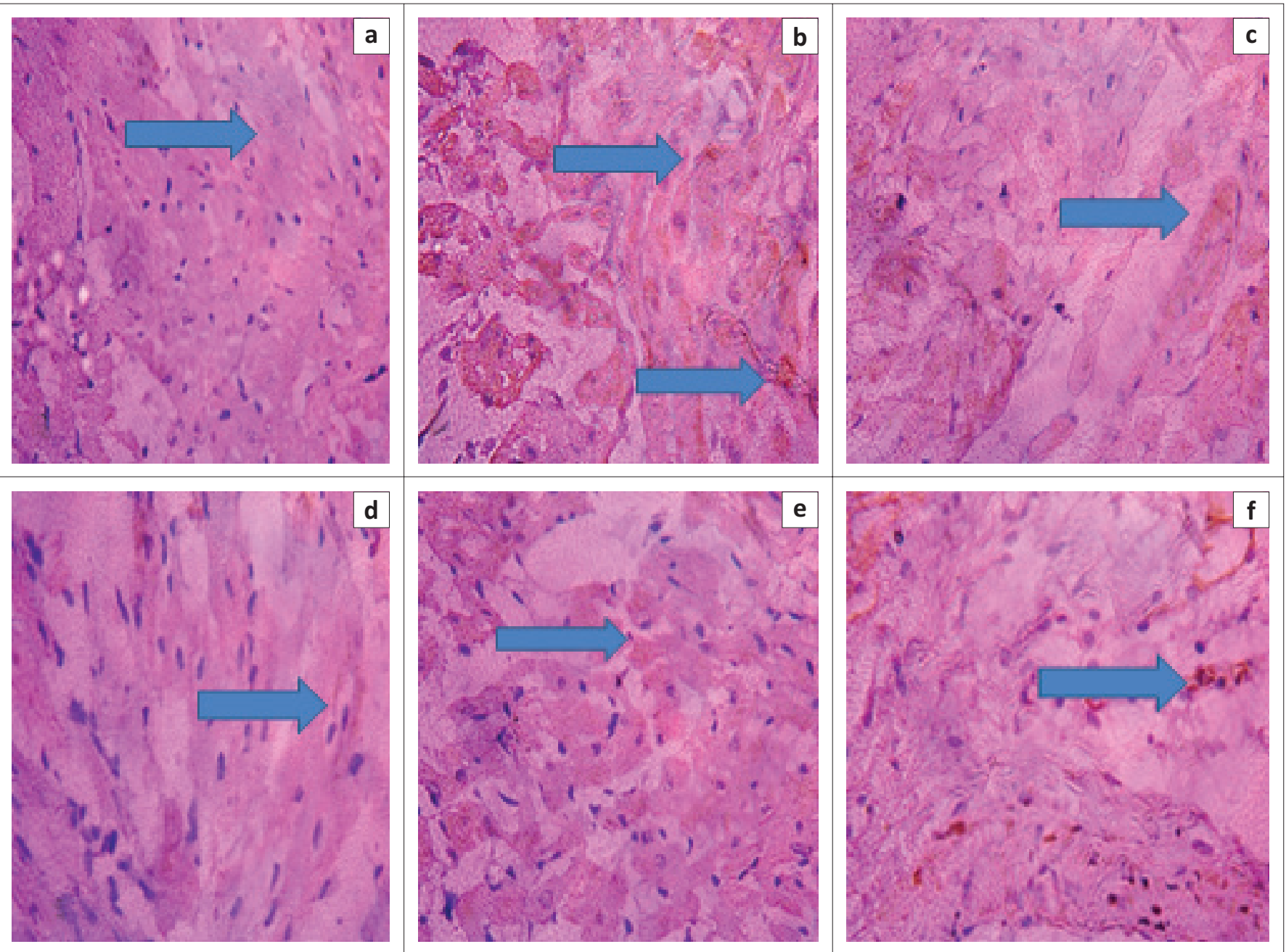

(a) Control - shows positive and low expression of CTnI. (b) ISO - shows higher expression of CTnl than control. (c) $100 \mathrm{mg} / \mathrm{kg}+\mathrm{ISO}$, (d) $200 \mathrm{mg} / \mathrm{kg}+\mathrm{ISO}$, (e) $400 \mathrm{mg} / \mathrm{kg}+\mathrm{ISO}$ and (f) ISO + 200 mg/ $\mathrm{kg}$ - show lower expression of cTn than (b). The slides were counterstained with high-definition haematoxylin. Mag. x100.

FIGURE 14: Immunohistochemistry of cardiac troponin in heart of isoproterenol-induced myocardial infarction rats.

TABLE 2: Effects of the ethanolic leaf extract of Andrographis paniculata on ALT, AST and nitric oxide in isoproterenol-induced myocardial infarction in rats.

\begin{tabular}{|c|c|c|c|c|c|c|}
\hline \multicolumn{3}{|c|}{ Groupings } & \multicolumn{3}{|c|}{ Pre-treated groups } & \multirow{2}{*}{$\begin{array}{c}\text { Post-treated group } \\
200 \mathrm{mg} / \mathrm{kg}\end{array}$} \\
\hline Parameters & Control & ISO & $100 \mathrm{mg} / \mathrm{kg}$ & $200 \mathrm{mg} / \mathrm{kg}$ & $400 \mathrm{mg} / \mathrm{kg}$ & \\
\hline ALT (U/L) & $14.51 \pm 0.02$ & $14.67 \pm 0.05^{*}$ & $14.45 \pm 0.04 *, * *$ & $14.48 \pm 0.04 * *$ & $14.45 \pm 0.01 * *$ & $14.40 \pm 0.01 *, * *$ \\
\hline AST (U/L) & $19.91 \pm 0.01$ & $19.97 \pm 0.02 *$ & $19.88 \pm 0.02 * *$ & $19.88 \pm 0.01 *, * *$ & $19.88 \pm 0.02 *, * *$ & $19.87 \pm 0.02 *, * *$ \\
\hline NO ( $\mu$ mole/mg protein) & $4.11 \pm 0.68$ & $1.72 \pm 0.47 *$ & $4.16 \pm 0.27^{* *}$ & $3.41 \pm 0.19 * *$ & $2.91 \pm 0.56 *, * *$ & $3.07 \pm 0.34 *, * *$ \\
\hline
\end{tabular}

Note: Values are presented as mean \pm standard deviation.

*, indicates significant difference $(p<0.05)$ when compared with control $(\operatorname{Grp~A}) ; * *$, indicates significant difference $(p<0.05)$ when compared with ISO treated only (Grp B)

The proverbial mechanisms of ISO-induced MI include lipid metabolism disorders, large excess generation of ROS, oxidative stress as well as increased intracellular $\mathrm{Ca}^{2+}$ overload (Al-Yahya et al. 2013). Adrenochrome and other oxidation metabolites of catecholamines can cause cell necrosis and contractile failure in the rat's heart (Liaudet, Calderari \& Pacher 2014). In this study, ISO caused MI via the abnormalities in the generation of free radical and inflammation. This study was designed to evaluate the cardioprotective effects of EEAP on isoproterenol-induced MI in rats.

To understand the protective effect of EEAP on cardiac abnormalities, hemodynamic parameters were included into the experimental study. Isoproterenol caused an intensive myocardial necrosis along with a profound decrease in systolic blood pressure, diastolic blood pressure and mean arterial pressure. The significant decrease in the levels of systolic, diastolic and mean arterial pressure may lead to coronary hypotension as seen in this study. In a study by Owens and O'Brien (1999), it was concluded that in patients suffering from ischemic heart disease and hypotension, symptomatic and silent ischaemia occurred in a temporally causal relation with hypotension, particularly for diastolic pressures. It thus suggests that patients with coronary disease may be susceptible to ischemic events that could be incurred as a result of low blood pressure. This study demonstrated that EEAP at all doses significantly prevented isoproterenol-induced cardiac abnormalities.

The results of haematological analysis in this study showed that ISO caused significant increase in the levels of 

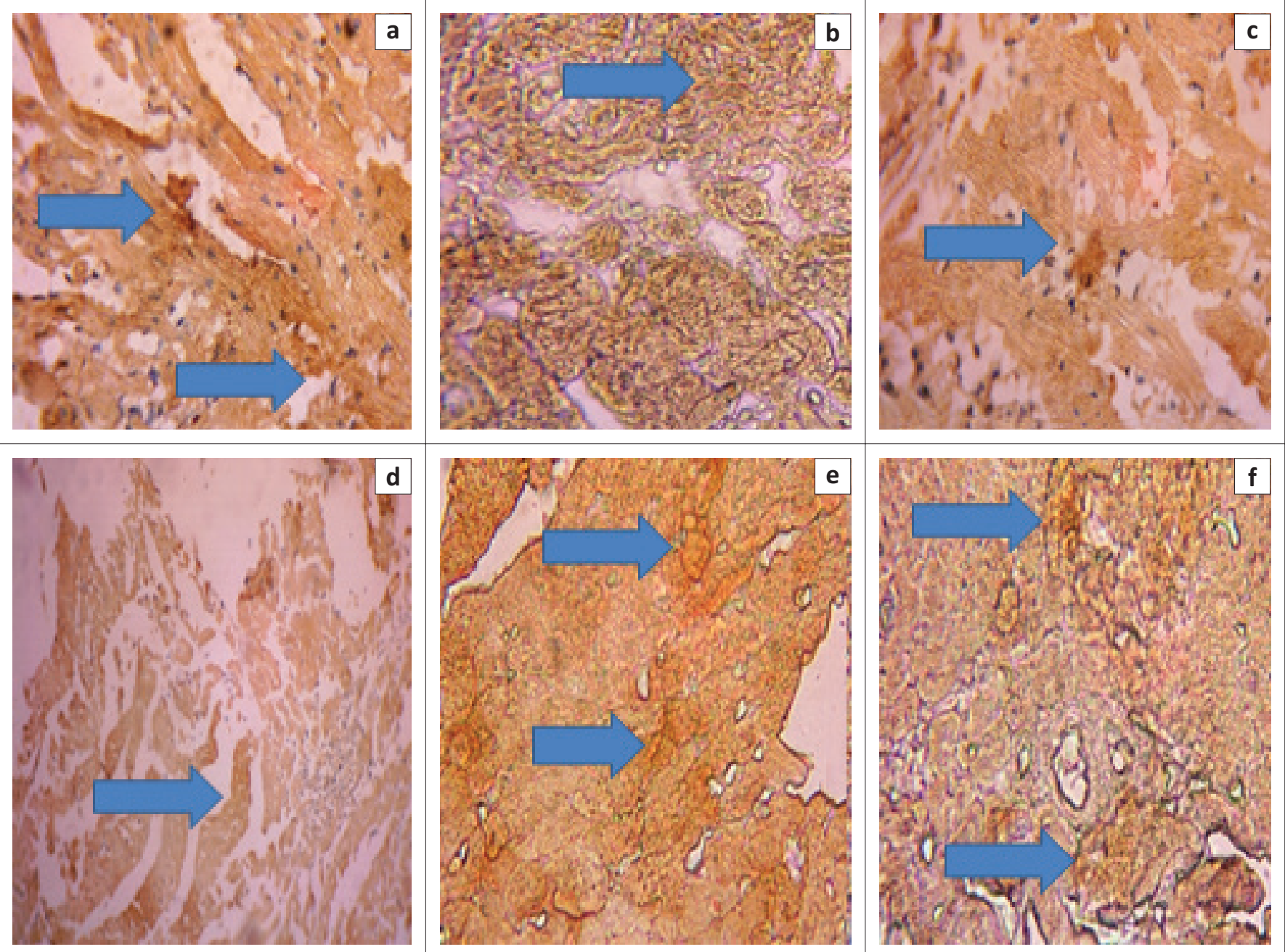

(a) Control - shows positive and low expression of CRP. (b) ISO - shows higher expression of CRP than control. (c) $100 \mathrm{mg} / \mathrm{kg}+\mathrm{ISO}$, (d) $200 \mathrm{mg} / \mathrm{kg}+\mathrm{ISO}$, (e) $400 \mathrm{mg} / \mathrm{kg}+\mathrm{ISO}$ and (f) ISO + $200 \mathrm{mg} /$ $\mathrm{kg}$ - show lower expression of CRP than (b). The slides were counterstained with high-definition haematoxylin. Mag. $\times 100$.

FIGURE 15: Immunohistochemistry of C-reactive protein in heart of isoproterenol-induced myocardial infarction rats.

white blood cells (WBC) and packed cell volume (PCV). The increase in the level of WBC could be explained in terms of necrosis caused by this agent leading to WBC mobilisation (Khalil et al. 2015). Ethanol extract of $A$. paniculata caused a significant increase in WBC, and this may be because of immunostimulant effect of the extract. This is in accordance with an earlier study by Adedapo, Obadan and Ohore (2009), where it was shown that an 800 $\mathrm{mg} / \mathrm{kg}$ dose of the aqueous extract of $A$. paniculata caused a significant increase in the levels of WBC. Handa and Sharma (1990) in their study also observed an increase in the level of WBC. Puri et al. (1993) were of the opinion that the increase in the levels of the WBC differentials may be because of the presence of andrographolide, which is said to possess immunostimulatory properties.

Use of high concentration of ISO had been reported to induce severe oxidative stress and result in necrotic lesions in the myocardium of rats (Rona 1959; Yerra et al. 2006). The increased generation of ROS and/or depletion of the antioxidants in the defence system may contribute to oxidative stress and affect the pathogenesis of MI (Sawyer et al. 2002). Free radical scavenging enzymes such as SOD and
GPx (Sawyer 2002) are the first-line cellular defence against oxidative stress, eliminating reactive oxygen radicals such as superoxide anion and hydrogen peroxide, and preventing the formation of more reactive radical of hydroxyl radical. In this study, rats pre-treated and post-treated with EEAP showed increased activities of these enzymes, which strongly suggested that EEAP has the ability to check the deleterious effects of free radicals in ISO-induced rats in agreement with the previous report by Sivakumar and Rajeshkumar (2015) which indicated that $A$. paniculata enhanced antioxidant enzymes.

GSH, protein thiol and non-protein thiol are non-enzymatic defences, which are important for maintaining cell integrity because of its reducing properties (Hadi et al. 2016). The function of GSH and thiols is to serve as the reductant of toxic peroxides and it also helps in keeping the enzymes in an active state by preventing the conversion of sulfhydryl group to disulphide group. In addition, GSH is a co-substrate for the detoxification of peroxides by GPx and of toxic metabolites by GSTs (Halliwell \& Gutteridge 1989). When there is deficiency or depletion of this enzyme, it causes damage to the macromolecules or membranes. The deficiency of GSH 

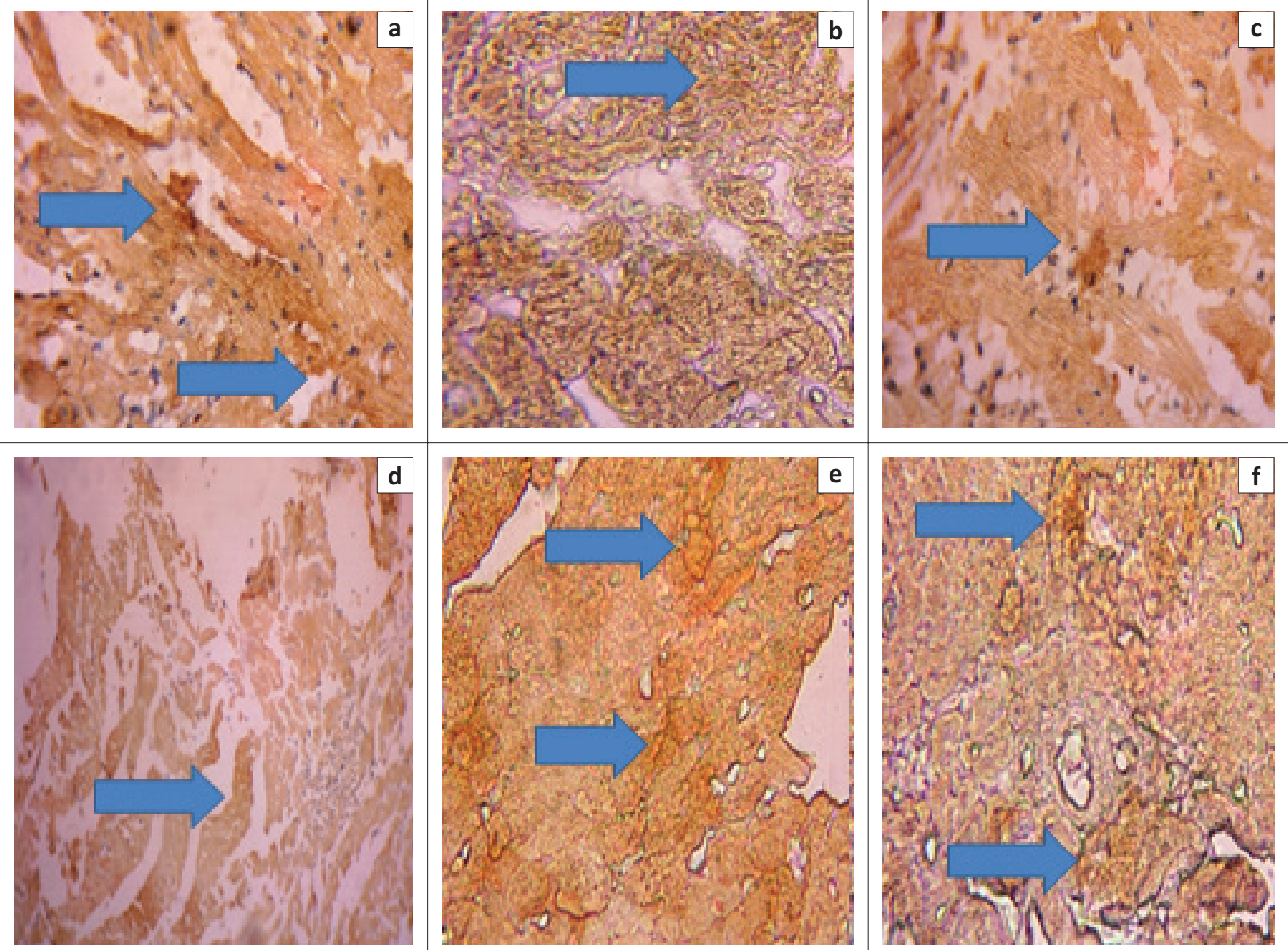

(a) Control - shows positive and higher expression of IL-10. (b) ISO - shows lower expression of IL-10 than control. (c) $100 \mathrm{mg} / \mathrm{kg}+\mathrm{ISO}$, (d) $200 \mathrm{mg} / \mathrm{kg}+\mathrm{ISO}$, (e) $400 \mathrm{mg} / \mathrm{kg}+\mathrm{ISO}$ and (f) ISO +200 $\mathrm{mg} / \mathrm{kg}$ - all show higher expression of IL-10 than (b). The slides were counterstained with high-definition haematoxylin. Mag. x100.

FIGURE 16: Immunohistochemistry of interleukin-10 in heart of isoproterenol-induced myocardial infarction rats.

caused by ISO indicates its interaction with biomembrane and subsequent peroxidising action. The inhibitory effect on depletion of GSH levels by pre-treatment and post-treatment with EEAP in rats further revealed the protective effect of this extract on isoproterenol-induced MI, and this effect may be because of the antioxidant property of EEAP. Hassan et al. (2017) have reported this and is thus a confirmation of the antioxidant effect of this extract.

Lipid peroxidation, an essential pathogenic event in myocardial necrosis, is a sensitive marker of oxidative stress induced by ISO. Increased level of MDA, one of the lipid peroxidation end products, reflects the intensity of damage of cardiac constituents (Khalil et al. 2015). Malondialdehyde level is commonly used as a marker of oxidative stress (Maddock \& Pariante 2001). In this study, there was an increase in MDA level in the ISO treated group, and previous studies have reported that ISO-induced MI could be as a result of induction of free radical-mediated lipid peroxidation, because of stress condition in rats (Zhou et al. 2016). The results presented in this study indicated that EEAP could decrease ISO-induced MDA content elevation. The decreased level of MDA in heart tissues might be because of the enhanced activities in antioxidant enzymes like SOD and GPx. It is quite possible that the free radicals induced by ISO were effectively neutralised and/or scavenged, resulting in the cardioprotective effect of EEAP.

After the onset of damage to myocytes as a result of deficient oxygen or glucose supply and oxidative stress caused by ISO, the cardiac membranes become permeable or even rupture, which results in the leakage of enzymes (Selaraj \& Pugalendi 2012). Consequently, the myocardial enzymogram in serum changes constitutes an index to ascertain the alterations of membrane integrity and degree of myocardial injury caused by oxidative stress (Wang et al. 2016). Myeloperoxidase (MPO) is abundant in the granules of inflammatory cells, and it is an important enzyme in the generation of ROS by conversion of hydrogen peroxide to species including $\bullet \mathrm{OH}$, $\mathrm{ONOO}-$, hypochlorous acid $(\mathrm{HOCl})$ and $\mathrm{NO}_{2}$ (Furtmuller et al. 2003; Zederbauer et al. 2007). Hydrogen peroxide $\left(\mathrm{H}_{2} \mathrm{O}_{2}\right)$, an ROS, has been suggested as a mediator of vascular structural and functional alterations observed in hypertension (Alvarez et al. 2007). This study revealed that ISO caused high MPO activity, indicative of necrosis-induced inflammation of cardiac tissue. Treatment with EEAP at both 
pre-treatment and post-treatment phases was found to significantly lower ISO-induced elevation in the activity of MPO enzyme. This result is in agreement with the work of Adedapo et al. (2015) who reported anti-inflammatory properties of $A$. paniculata.

Once the cardiomyocytes were injured because of ISO administration, this would be followed by disruption of associated cell membranes, and these intracellular proteins were then released into the circulation, promptly increasing the serum levels of these enzymes during the acute phase of necrosis. Although AST and ALT are not specific enzymes for MI because of their wide distribution in the body, they can be used as an early predictor of tissue damage (Dianita et al. 2015). In this study, we observed an increase in the serum activities of AST and ALT in rats treated with ISO. The release of cellular enzymes reflects the alterations in plasma membrane integrity and/or permeability as a response to $\alpha$-adrenergic stimulation. This might be because of the damage caused to the sarcolemma by the $\alpha$-agonist that has rendered it leaky. Isoproterenol induction produces free radicals via adrenoceptor mechanism and affects the cell metabolism to such a degree that cytotoxic free radicals are formed, producing myocardial necrosis (Upaganlawar et al. 2011). Ethanol extract of $A$. paniculata decreased the activities of these enzymes in serum. This could be because of the protective effect of EEAP on the myocardium, thus reducing the cardiac damage thereby restricting the leakage of these enzymes.

Furthermore, to elucidate the possible mechanism of EEAP on ISO-induced MI, serum NO was evaluated. Nitric Oxide may play a critical part in cardiac injury and hypertrophy (Yang et al. 2011). For instance within the vasculature, NO induces vasodilation, inhibits platelet aggregation, prevents neutrophil or platelet adhesion to endothelial cells, inhibits smooth muscle cell proliferation and migration, regulates programmed cell death (apoptosis) and maintains endothelial cell barrier function (Rosselli, Keller \& Dubey 1998). NO is known to be deficient in chronic progressive renal disease (CRD) and in end-stage renal failure (ESRD) (Reyes, Karl \& Klahr 1994), and this could result from arginine deficiency (Rosselli et al. 1998) which may be caused by a loss of functional renal mass, increased endogenous NO synthase (NOS) inhibitors that accumulate in renal failure (Vallance et al. 1992) and/or other causes, such as increased oxidant stress (Vaziri, Ovelisi \& Ding 1998). Low NO production may also contribute to and/or exacerbate the progression of CRD by both hemodynamic and renal growth-promoting actions (Schmidt \& Baylis 2000). This study demonstrated that serum NO level was increased in EEAP treated rats. Previous study in eNOS-over expressed mouse model had proved that released NO can attenuate ISO-induced hypertrophy (Ozaki et al. 2002).

Cardiac troponin T has been shown to be highly specific and a sensitive marker in the determination of myocardial cell injury. The studies by O'Brien et al. (1997) and Adamcova et al. (2016) have shown that cTnT is a powerful biomarker in laboratory animals for sensitive and specific detection of cardiac injury arising from various causes. In this study, there is an increase in the expression of CTnI in heart tissue of rats treated with ISO. This increase in troponin expression predicts the risk of both cardiac death and subsequent infarction. The observation of the increased expression of $\mathrm{CTnI}$ in heart tissue of rats treated with ISO is consistent with similar reports by Acikel et al. (2005) and Othman et al. (2017). In this study, treatment with EEAP decreased the expression of CTnI in heart tissue of ISO-induced MI in rats. Down regulation of cardiac troponin by EEAP showed the ability to protect against myocardial injury in rats. This could be because of the reduction of the degree of damage in the myocardium by the drug and EEAP.

Increased expression and plasma concentrations of inflammatory markers and mediators are seen in patients suffering from cardiovascular diseases (Blake \& Ridker 2001; Sesso et al. 2003). C-reactive protein, in particular, has been demonstrated as an independent risk factor for the development of hypertension. Epidemiological studies have shown that plasma levels of high-sensitivity CRP (hsCRP) are a powerful predictor of ischemic cardiovascular events in patients with stable or unstable angina (Blake et al. 2003; Thorand et al. 2003). C-reactive protein has also been associated with increased risk of diabetes (Barzilay, Peterson \& Cushman 2004). Several studies report that the level of CRP significantly increased in acute MI (Kim et al. 2016). CRP is a known marker of systemic inflammation, which has been linked with an increased risk of MI, and potentially vital device in primary prevention of CVD (Itrat et al. 2017). It was the first acute phase protein to be described and is an exquisitely sensitive systemic marker of inflammation and tissue damage (Rosselli et al. 1998). In this study, there is increased expression of CRP in ISO treated rats. In acute myocardial infarcts, CRP is co-deposited with activated complement (Lagrand et al. 1997), and research findings have shown that the CRP response did not only reflect tissue damage in this context but may significantly contribute to the severity of ischemic myocardial injury (Griselli et al. 1999). It is very clear that CRP plays a role in the pathogenesis of cardiovascular disease, and as a marker and predictor of cardiovascular disease, CRP possesses numerous cardiovascular effects including clotting, generation of oxygen radicals, increase in the expression of adhesion molecules and plasminogen activator inhibitor-1, and plaque destabilisation, and these could result in cardiovascular disease. The lowering of the level of CRP in this study by EEAP is a pointer to its ability to halt cardiovascular disease, hence the cardioprotective effect through its antioxidant and antiinflammatory properties.

In addition to homeostasis of proinflammatory and antiinflammatory effects, cytokines play a major role in cardiac pathophysiological conditions like MI (Ono et al. 1998). IL-10 is a $\mathrm{Th}_{2}$-type cytokine that is produced by a wide range of immunological cell types, including monocytes or macrophages, and it is a potent inhibitor of the proinflammatory cytokines and chemokines (Akdis \& Blaser 2001). Interestingly, in this study, there was an increase of IL-10 in heart tissues of rats both at pre-treatment 
and post-treatment phases with EEAP suggesting its cardioprotective effect.

ISO-induced MI is also manifested by altered histopathological features including marked necrosis, severe infiltration of inflammatory cells and disorganisation of myocardium. This increase in the inflammatory cells may have been responsible for the increase in the levels of WBC noted in this study. In the study on the ISO-induced myocardial damage, it was discovered that the cardiac lesions varied with treatment duration and doses and that numerous macrophages were observed in the necrotic areas (Zhang et al. 2008). The normal control rats showed normal cardiac fibres without any infiltration of inflammatory cells, whereas the tissues from EEAP treated rats showed a near normal myocardium (Figure 13).

\section{Conclusion}

The results from this study indicated that the ethanol leaf extract of A. paniculata has a protective effect on isoproterenolinduced MI. Amongst the groups treated with ISO $(85 \mathrm{mg} /$ $\mathrm{kg}$ ) and EEAP, the best results were achieved in the EEAP $(\mathrm{ISO}+200 \mathrm{mg} / \mathrm{kg}$ ) group. Thus, these findings indicate that EEAP has a cardioprotective effect against isoproterenolinduced $\mathrm{MI}$ in rats.

\section{Acknowledgements}

This study was supported by a grant from the National Research Foundation of the Tertiary Education Trust Fund (TETFUND), Abuja, Nigeria (TETFUND/DESS/NRF/UI IBADAN/STI/VOL. 1/B2.20.11).

\section{Competing interests}

The authors declare that they have no financial or personal relationships, which may have inappropriately influenced them in writing this article.

\section{Authors' contributions}

B.O.A., T.O.A., A.D.A., A.A.O. and T.O.O. performed the experiments. A.A.A. was the project leader and along with A.E.A. and M.A.Y. designed the experiment. A.A.A. drafted the manuscript and all authors read and approved the final draft.

\section{References}

Acikel, M., Buyukokuroglu, M.E., Erdogan, F., Aksoy, H., Bozkurt, E. \& Senocak, H., 2005, 'Protective effects of dantrolene against myocardial injury induced by isoproterenol in rats: Biochemical and histological findings', International Journal of Cardiology 98(3), 389-394. https://doi.org/10.1016/j.ijcard.2003.10.054

Adamcova, M., Popelova Lencova, O., Jirkovsky, E., Simko, F., Gersl, V. \& Sterba, M. 2016, 'Cardiac troponins-Translational biomarkers in cardiology: Theory and practice of cardiac troponin high sensitivity assays', Biofactors 42(2), 133-148.

Adameova, A., Abdellatif, Y. \& Dhalla, N.S., 2009, 'Role of excessive amounts of circulating catecholamines and glucocorticoids in stress induced heart disease', Canadian Journal of Physiology and Pharmacology 87, 493-514. https://doi. org/10.1139/Y09-042

Adedapo, A.A., Adeoye, B.O., Sofidiya, M.O. \& Oyagbemi, A.A., 2015, 'Antioxidant antinociceptive and anti-inflammatory properties of the aqueous and ethanol leaf extract of Andrographis paniculata in some laboratory animals', Journal of Basic Clinical Physiology and Pharmacology 26(4), 327-334. https://doi.org/10.1515/ jbcpp-2014-0051
Adedapo, A.A., Obadan, A.Y. \& Ohore, O.G., 2009, 'Some toxicological effects of the aqueous leaf extract of Andrographis paniculata in rats', Tropical Veterinarian 27, 1-9.

Akbar, S., 2011, 'Andrographis paniculata: A review of pharmacological activities and clinical effects', Alternative Medicine Review 16, 66-77.

Akdis, C.A. \& Blaser, K., 2001, 'Mechanisms of interleukin-10-mediated immune suppression', Immunology 103, 131-136. https://doi.org/10.1046/j.13652567.2001.01235.x

Akowuah, G.A., Zhari, I. \& Mariam, A., 2008, 'Analysis of urinary andrographolides and antioxidant status after oral administration of Andrographis paniculata leaf extract in rats', Food Chemistry Toxicology 46(12), 3616-3620. https://doi. org/10.1016/j.fct.2008.09.008

Alvarez, Y., Pe'rez-Giro'n, J.V., Hernanz, R., Briones, A.M., García-Redondo, A. et al. 2007, 'Losartan reduces the increased participation of cyclooxygenase-2-derived products in vascular responses of hypertensive rats', Journal of Pharmacology and Experimental Therapeutics 321, 381-388. https://doi.org/10.1124/jpet. 106.115287

Al-Yahya, M.A., Mothana, R.A., Al-Said, M.S., El-Tahir, K.E., Al-Sohaibani, M. \& Rafatullah, S., 2013, 'Citrus medica Otroj: Attenuates oxidative stress and cardiac dysrhythmia in isoproterenol-induced cardiomyopathy in rats', Nutrients 5(11), 4269-4283. https://doi.org/10.3390/nu5114269

Barzilay, J.I., Peterson, D. \& Cushman, M., 2004, 'The relationship of cardiovascular risk factors to microalbuminuria in older adults with or without diabetes mellitus or hypertension: The cardiovascular health study', American Journal of Kidney Diseases 44, 25-34. https://doi.org/10.1053/j.ajkd.2004.03.022

Beutler, E. \& Kelly, B.M., 1963, 'The effect of sodium nitrite on red cell GSH', Cellular and Molecular Life Science 19(2), 96-97. https://doi.org/10.1007/BF02148042

Blake, G.J., Rifai, N., Buring, J.E. \& Ridker, P.M., 2003, 'Blood pressure, C-reactive protein, and risk of future cardiovascular events', Circulation 108, 2993-2999. https://doi.org/10.1161/01.CIR.0000104566.10178.AF

Blake, J.G. \& Ridker, P.M., 2001, 'Novel clinical markers of vascular wall inflammation', Circulatory Research 89, 763-771. https://doi.org/10.1161/hh2101.099270

Chen, H., Azuma, M., Maeda, K., Kajimoto, N. \& Higashino, H., 2000, 'Impaired heart function and noradrenaline release after ischaemia in stroke-prone spontaneously hypertensive rats', Clinical and Experimental Pharmacology and Physiology 27, 664-670. https://doi.org/10.1046/j.1440-1681.2000.03325.x

Dianita, R., Jantan, I., Amran, A.Z. \& Jalil, J., 2015, 'Protective effects of Labisia pumila var. alata on biochemical and histopathological alterations of cardiac muscle cells in isoproterenol-induced myocardial infarction in rats', Molecules 47, 4746-4763. https://doi.org/10.3390/molecules20034746

Drury, R., Wallington, E. \& Cancerson, R., 1976, Carleton's histological technique, 4th edn., Oxford University Press, London.

Ellman, G.L., 1959, 'Tissue sulfhydryl groups', Archives of Biochemistry and Biophysics 82(1), 70-77. https://doi.org/10.1016/0003-9861(59)90090-6

Furtmuller, P.G., Arnhold, J., Jantschko, W., Pichler, H. \& Obinger, C., 2003, 'Redox properties of the couples compound $1 /$ compound II and compound II/native enzyme of human myeloperoxidase', Biochemical and Biophysical Research enzyme of human myeloperoxidase, Biochemical and Biophysical Research
Communication 301, 551-557. https://doi.org/10.1016/S0006-291X(02)03075-9

Gornal, A.G., Bardawill, J.C. \& David, M.M., 1949, 'Determination of serum proteins by means of Biuret reaction', Journal of Biological Chemistry 177, 751-766.

Griselli, M., Herbert, J., Hutchinson, W.L., Taylor, K.M., Sohail, M., Krausz, T. et al., 1999, 'C-reactive protein and complement are important mediators of tissue damage in acute myocardial infarction', Journal of Experimental Medicine 190, 1733-1739. https://doi.org/10.1084/jem.190.12.1733

Habig, W.H., Pabst, M.J. \& Jacoby, W.B., 1974, 'Glutathione-S-transferase activity: The enzymic step in mercapturic acid formation', Journal of Biological Chemistry 249, 130-139.

Hadi, S., Mirmiran, P., Hadi, V., Hosseinpour-Niazi, S. \& Emamat, S.M., 2016, 'Effects of Nigella sativa on Cardiovascular Risk Factors', Journal Medical Science 25(134), 430-442.

Halliwell, B. \& Gutteridge, J.M., 1989, 'Protection against oxidants in biological systems: The superoxide theory of oxygen toxicity', Free Radicals in Biology and Medicine, 2nd edn., 87-187.

Handa, S.S. \& Sharma, A., 1990, 'Hepatoprotective activity of andrographolide against galactosamine and paracetamol intoxication in rats', Indian Journal of Medical Research 92, 284-292.

Hassan, S.M., Khalaf, M.M., Sadek, S.A. \& Abo-Youssef, A.M., 2017, 'Protective effects of apigenin and myricetin against cisplatin-induced nephrotoxicity in mice', Journal of Pharmaceutical and Biomedical Analysis 55(1), 766-774. https://doi.or $\mathrm{g} / 10.1080 / 13880209.2016 .1275704$

Hossain, M.S., Urbi, Z., Sule, A. \& Hafizur-Rahman, K.M., 2014, 'Andrographis paniculata (Burm. f.) Wall. ex Nees: A review of ethnobotany, phytochemistry, and pharmacology', Scientific World Journal, 1-28. https://doi.org/10.1155/ 2014/274905

Hussein, M.A., 2015, 'Cardioprotective effects of Astaxanthin against IsoproterenolInduced cardiotoxicity in Rats', Journal of Nutrition and Food Science 5, 335.

Itrat, A., Griffith, S.D., Alam, S., Thompson, N. \& Katzan, I.L., 2017, 'The role of very high high-sensitivity C-reactive protein levels on mortality after stroke', Journal of Biological Chemistry 372, 1-5. https://doi.org/10.1016/j.jns.2016.11.019

Jayakumar, T., Hsieh, C.Y., Lee, J.J. \& Sheu, J.R. 2013, 'Experimental and clinical pharmacology of Andrographis paniculata and its major bioactive phytoconstituent andrographolide', Evidence-Based Complementary and Alternative Medicine $1-16$. 
Kamdem, R.E., Sang, S. \& Ho, C.T., 2002, 'Mechanism of the superoxide scavenging activity of neoandrographolide-a natural product from Andrographis paniculata nees', Journal of Agricultural and Food Chemistry 50(16), 4662-4665. https://doi. org/10.1021/jf025556f

Khali,, M.I., Ahmmed, I., Ahmed, R., Tanvir, E.M., Afroz, R., Paul, S. et al., 2015, 'Amelioration of isoproterenol-induced oxidative damage in rat myocardium by Withania somnifera leaf extract' Biomedical Research International 24159, 1-10.

Kim, D., Choi, D.H., Kim, B.B., Choi, S.W., Park, K.H. \& Song, H., 2016, 'Prediction of infarct transmurality from c-reactive protein level and mean platelet volume in patients with ST elevation myocardial infarction: Comparison of the predictive values of cardiac enzymes', Journal of Clinical Laboratory Analysis 30(6), 930-940. https://doi.org/10.1002/jcla.21959

Lagrand, W.K., Niessen, H.W., Wolbink, G.J., Jaspars, L.H., Visser, C.A., Verheugt, F.W. et al., 1997, 'C-reactive protein colocalizes with complement in human hearts during acute myocardial infarction', Circulation 95, 97-103. https://doi.org/10.1161/01. CIR.95.1.97

Liaudet, L., Calderari, B. \& Pacher, P., 2014, 'Pathophysiological mechanisms of catecholamine and cocaine-mediated cardiotoxicity', Heart Failure Reviews 19(6), 815-824. https://doi.org/10.1007/s10741-014-9418-y

Maddock, C. \& Pariante, C.M., 2001, 'How does stress affect you? An overview of stress, immunity, depression, and disease', Epidemiologia Psychiatria Sociale 10(3), 153-162. https://doi.org/10.1017/S1121189X00005285

Misra, H.P. \& Fridovich, I., 1972, 'The role of superoxide anion in the autoxidation of epinephrine and a simple assay for superoxide dismutase', Journal of Biological Chemistry 247(10), 3170-3175.

Murugesan, M., Ragunath, M., Prabu, T., Nadanasabapathi, S., Sakthivel, M. \& Manju V., 2012, 'Protective role of black cumin (Nigella sativa) on isoproterenol induced myocardial infarction in rats', International Journal of Pharmacology and Clinical Science 1, 45-53.

O'brien, P.J., Dameron, G.W., Beck, M.L., Kang, Y.J., Erickson, B.K., Di Battista, T.H. et al., 1997, 'Cardiac troponin $\mathrm{T}$ is a sensitive, specific biomarker of cardiac injury in laboratory animals', Complementary Medicine 47(5), 486-495.

Olaleye, S.B., Adaramoye, O.A. \& Erigbali, P.P., 2007, 'Lead exposure increases oxidative stress in the gastric mucosa of $\mathrm{HCl} /$ ethanol-exposed rats', World Journal of Gastroenterology 13, 5121-5126. https://doi.org/10.3748/wjg.v13.i38.5121

Ono, K., Matsumori, A., Shioi, T., Furukawa, Y. \& Sasayama, S., 1998, 'Cytokine gene expression after myocardial infarction in rat hearts', Circulation 98(2), 149-156. https://doi.org/10.1161/01.CIR.98.2.149

Othman, A.I., Elkomy, M.M., El-Missiry, M.A. \& Dardor, M. 2017, 'Epigallocatechin-3 gallate prevents cardiac apoptosis by modulating the intrinsic apoptotic pathway in isoproterenol-induced myocardial infarction', European Journal of Pharmacology 794, 27-36. https://doi.org/10.1016/j.ejphar.2016.11.014

Owens, P. \& O'Brien, E., 1999, 'Hypotension in patients with coronary disease: Can profound hypotensive events cause myocardial ischaemic events?', Heart 82 477-481. https://doi.org/10.1136/hrt.82.4.477

Ozaki, M., Kawashima, S., Yamashita, T., Hirase, T., Ohashi, Y. \& Inoue, N., 2002, 'Overexpression of endothelial nitric oxide synthase attenuates cardiac hypertrophy induced by chronic isoproterenol infusion', Circulation 66(9), 851856. https://doi.org/10.1253/circj.66.851

Parixit, B., Bharath, C., Rajarajeshwari, N. \& Ganapaty, S., 2012, 'The genus Andrographis - a review', International Journal of Pharmaceutical Sciences 4 1835-1856.

Puri, A., Saxena, R., Saxena, R.P. \& Saxena, K.C., 1993, 'Immunostimulant agents from Andrographis paniculata', Journal of Natural Products 56(7), 995-999. https://doi. org/10.1021/np50097a002

Reyes, A.A., Karl, I.E. \& Klahr, S., 1994, 'Role of arginine in health and in renal disease', American Journal of Physiology 267, 331-346. https://doi.org/10.1152/ ajprenal.1994.267.3.F331

Reyes, B.A., Bautista, N.D., Tanquilut, N.C., Anunciado, R.V., Leung, A.B., Sanchez, G.C et al., 2006, 'Anti-diabetic potentials of Momordica charantia and Andrographis paniculata and their effects on estrous cyclicity of alloxan-induced diabetic rats', Journal of Ethnopharmacology 105, 96. https://doi.org/10.1016/j.jep.2005.10.018

Rona, G., 1985, 'Catecholamine cardiotoxicity', Journal of Molecular and Cellular Cardiology 17(4), 291-306. https://doi.org/10.1016/S0022-2828(85)80130-9

Rona, G., Chappel, C.I., Balazs, T. \& Gaudry, R., 1959, 'An infarct like myocardial lesion and other toxic manifestations produced by isoproterenol in the rat', Archives of Pathology 76, 443-445.

Rosselli, M., Keller, P.J. \& Dubey, R.K., 1998, 'Role of nitric oxide in the biology, physiology and pathophysiology of reproduction', Human Reproduction 4(1), 3-24. https://doi.org/10.1093/humupd/4.1.3

Rotruck, J.T., Pope, A.L., Ganther, H.E., Swanson, A.B., Hafeman, D.G. \& Hoekstra, W.G., 1973, 'Selenium biochemical role as a component of glutathione peroxidase', Science 179, 588-590. https://doi.org/10.1126/science.179.4073.588

Sawyer, D.B., Siwik, D.A., Xiaol, L., Pimentel, D.R., Singh, K. \& Colucci, W.S., 2002, 'Role of oxidative stress in myocardial hypertrophy and failure', Journal of Molecular

Schmidt, R.J. \& Baylis, C., 2000, 'Total nitric oxide production is low in patients with chronic renal disease', Kidney International 58(3), 1261-1266. https://doi. org/10.1046/j.1523-1755.2000.00281.x

Selaraj, P. \& Pugalendi, K.V., 2012, 'Efficacy of hesperidin on plasma, heart and liver tissue lipids in rats subjected to isoproterenol-induced cardiotoxicity' Experimental and Toxicologic Pathology 64, 449-452. https://doi.org/10.1016/j. etp.2010.10.012
Sesso, H.D., Buring, J.E., Rifai, N., Blake, G.J., Gaziano, J.M. \& Ridker, P.M., 2003, 'C-reactive protein and the risk of developing hypertension', Journal of American Medical Association 290, 2945-2951. https://doi.org/10.1001/jama.290.22.2945

Sheeja, K. \& Kuttan, G., 2007, 'Activation of cytotoxic T lymphocyte responses and attenuation of tumor growth in vivo by Andrographis paniculata extract and andrographolide', Immunopharmacology and Immunotoxicology 29, 81. https:// doi.org/10.1080/08923970701282726

Singh, R.P., Banerjee, S. \& Rao, A.R., 2001, 'Modulatory influence of Andrographis paniculata on mouse hepatic and extrahepatic carcinogen metabolizing enzymes and antioxidant status', Phytotherapy Research 15(5), 382-390. https://doi. org/10.1002/ptr.730

Sivakumar, V. \& Rajeshkumar, S., 2015, 'Protective effect of Andrographis paniculato on hyperglycemic mediated oxidative damage in renal tissues of diabetic rats', Journal of Phytopharmacology 4(6), 287-294.

Tan, W.D., Peh, H.Y., Liao, W., Pang, C.H., Chan, T.K., Lau, S.H. et al., 2016, 'Cigarette smoke-induced lung disease predisposes to more severe infection with nontypeable Haemophilus influenzae: Protective effects of andrographolide', Journal of Natural Products 79(5), 1308-1315. https://doi.org/10.1021/acs. jnatprod.5b01006

Thorand, B., Lowel, H., Schneider, A., Kolb, H., Meisinger, C., Frohlich, M. et al., 2003. 'C-reactive protein as a predictor for incident diabetes mellitus among middleaged men: Results from the MONICA Augsburg cohort study, 1984-1998', Archives of Internal Medicine 163, 93-99. https://doi.org/10.1001/archinte.163.1.93

Trivedi, N.P. \& Rawal, U.M., 2001, 'Hepatoprotective and antioxidant property of Andrographis paniculata (Nees) in BHC induced liver damage in mice', Indian Journal of Experimental Biology 39, 41.

Upaganlawar, A. \& Balaraman, R., 2011, 'Cardioprotective effects of Lagenaria siceraria fruit juice on isoproterenol-induced myocardial infarction in Wistar rats: A biochemical and histoarchitecture study', Journal of Young Pharmacists 3, 297303. https://doi.org/10.4103/0975-1483.90241

Upaganlawar, A., Gandhi, H. \& Balaraman, R., 2011, 'Isoproterenol induced myocardial infarction: Protective role of natural products', Journal of Pharmacology and Toxicology 6, 1-17. https://doi.org/10.3923/jpt.2011.1.17

Vallance, P., Leone, A., Calver, A., Collier, J. \& Moncada, S., 1992, 'Accumulation of an endogenous inhibitor of nitric oxide synthesis in chronic renal failure' Lancet 339, 572-575. https://doi.org/10.1016/0140-6736(92)90865-Z

Varshney, R. \& Kale, R.K., 1990, 'Effect of calmodulin antagonists on radiation induced lipid peroxidation in microsomes', International Journal of Biology 158, 733-741. https://doi.org/10.1080/09553009014552121

Vaziri, N.D., Ovelisi, F. \& Ding, Y., 1998, 'Role of increased oxygen free radical activity in the pathogenesis of uremic hypertension', Kidney International 53, 1748-1754. https://doi.org/10.1046/j.1523-1755.1998.00947.x

Verma, N. \& Vinayak, M., 2008, 'Antioxidant action of Andrographis paniculata on lymphoma', Molecular Biology Reports 35(4), 535-540. https://doi.org/10.1007/ s11033-007-9119-x

Wang, Z., Zhang, J., Ren, T. \& Dong, Z., 2016, 'Targeted metabolomic profiling of cardioprotective effect of Ginkgo biloba L. extract on myocardial ischemia in rats', Phytomedicine 23(6), 621-631. https://doi.org/10.1016/j.phymed.2016.03.005

Wolff, S.F., 1994, 'Ferrous ion oxidation in the presence of ferric ion indicator xyleno orange for measurement of hydrogen peroxides', Methods Enzymology 233, 182189. https://doi.org/10.1016/S0076-6879(94)33021-2

Yang, A.L., Lo, C.W., Lee, J.T. \& Su, C.T., 2011, 'Enhancement of vasorelaxation in hypertension following high-intensity exercise', Chinese Journal of Physiology 54(2), 87-95. https://doi.org/10.4077/CJP.2011.AMM011

Yerra, L., Anavekar, N., Skali, H., Zelenkofske, S., Velazquez, E., McMurray, J. et al., 2006, 'Association of QRS duration and outcomes after myocardial infarction: The VALIANT trial', Heart Rhythm 3(3), 313-316. https://doi.org/10.1016/j. hrthm.2005.11.024

Yogeeta, S.K., Raghavendran, H.R., Gnanapragasam, A., Subhashini, R. \& Devaki, T. 2006, 'Ferulic acid with ascorbic acid synergistically attenuates the mitochondrial dysfunction during $\beta$-adrenergic catecholamine induced cardiotoxicity in rats', Chemico-Biological Interaction 163, 160-169.

Zederbauer, M., Furtmüller, P.G., Brogioni, S., Jakopitsch, C., Smulevich, G. \& Obinger, C., 2007, 'Heme to protein linkages in mammalian peroxidases: Impact on spectroscopic, redox, and catalytic properties', Natural Product Reports 24, 571584. https://doi.org/10.1039/B604178G

Zhang, C.Y. \& Tan, B.K.H., 1997, 'Mechanisms of cardiovascular activity of Andrographis paniculata in the anaesthetized rat', Journal of Ethnopharmacology 56(2), 97101. https://doi.org/10.1016/S0378-8741(97)01509-2

Zhang, J., Knapton, A., Lipshultz, S.E., Weaver, J.L. \& Herman, E.H., 2008, 'Isoproterenolinduced cardiotoxicity in Sprague-Dawley rats: Correlation of reversible and irreversible myocardial injury with release of cardiac troponin T and roles of iNOS in myocardial injury', Toxicologic Pathology 36, 277-288. https://doi. org/10.1177/0192623307313010

Zhang, X.F. \& Tan, B.K.H., 2000, 'Anti-diabetic property of ethanolic extract of Andrographis paniculata in streptozotocin diabetic rats', Acta Pharmacologica Sinica 21(12), 1157-1164

Zhou, W., Xiao, Z., Wen, X., Luo, J., Chen, S., Cheng, Z. et al., 2016, 'The antiinflammatory effect of Andrographis paniculata (Burm. f.) Nees on pelvic inflammatory disease in rats through down-regulation of the NF-KB pathway', BMC Complementary and Alternative Medicine 16, 483-490. https://doi. org/10.1186/s12906-016-1466-5 